\title{
Práticas de lazer e espaços públicos de convivência como potência protetiva na relação entre juventude e risco
}

\author{
Daiana Cristina Sebenello \\ Universidade Comunitária da Região de Chapecó (Unochapecó)
}

Liane Keitel

Universidade Federal de Santa Catarina (UFSC)

\author{
Maria Elisabeth Kleba \\ Universidade Comunitária da Região de Chapecó (Unochapecó)
}

Práticas de lazer e espaços públicos de convivência como potência protetiva na relação entre juventude e risco

Resumo: Este artigo debate relações entre juventude, lazer e risco em uma perspectiva ampliada a partir de uma inquietação de profissionais da Rede de Atendimento à Infância e Adolescência (RAIA) de Chapecó no cotidiano de trabalho. O objetivo é entender o que jovens e seus pais, vinculados ao Serviço de Convivência de Fortalecimento de Vínculo, da Secretaria da Assistência Social de Chapecó, SC, reconhecem como práticas e locais de lazer e riscos associados. A pesquisa, de abordagem qualitativa, utiliza, para coleta dos dados, grupos focais, com resultados analisados a partir da identificação de temáticas centrais com base em referenciais teóricos. Palavras-Chave: Juventude. Práticas de Lazer. Risco. Vulneração e proteção.

Leisure Practices and Public Spaces for Conviviality as a Potential Form of Protection in the Relationship between Youth and Risk

Abstract: This article debates relationships between youth, leisure and risk in a broad perspective based on a concern of professionals who work daily in the Network of Care for Childhood and Adolescence (RAIA) of Chapecó. The objective is to understand what youths and their parents who have ties with the Conviviality Service for Strengthening Ties, of the Secretariat for Social Assistance of Chapecó, $\mathrm{SC}$, recognize as practices and locations of leisure and their associated risks. The qualitative research used focus groups to collect data. The results are analyzed by identifying central themes based on theoretical references.

Keywords: Youth. Leisure practices. Risk. Harm and protection. 


\section{Introdução}

Em 2012, em Chapecó, SC, iniciou-se uma Pós-Graduação em Proteção de Direitos e Trabalho em Rede para instrumentalizar profissionais da Rede de Atendimento a Infância e a Adolescência de Chapecó (RAIA). O projeto reuniu a Universidade Comunitária da Região de Chapecó (Unochapecó), por meio do Programa Nacional de Reorientação da Formação Profissional em Saúde, do Ministério da Saúde (Pró-Saúde), a Prefeitura Municipal, o Ministério Público, e outras instituições. A RAIA foi criada em 2006, em Chapecó, com intuito de ampliar a integração dos serviços de atendimento a infância e adolescência das políticas de saúde, educação e assistência social, promotoria pública entre outros. O público alvo desta formação foram profissionais envolvidos no desenvolvimento do trabalho em rede, buscando avançar na integração da rede e fortalecer conexões entre os serviços nos territórios e destes com serviços de referência e gestão no município. Nos encontros da RAIA são abordados problemas referentes à infância e juventude, chamando atenção falas de profissionais e famílias sobre práticas de lazer dos jovens nas quais estes estariam em riscos, principalmente, de consumo de álcool e drogas. Muitas vezes, o próprio lazer parece se confundir com risco.

Cabe situar brevemente as concepções de práticas de lazer, juventude e risco assumidas neste trabalho. O lazer, segundo Dumazedier (2001), são períodos de repouso, diversão, recreação, entretenimento, desenvolvimento da capacidade de criação, ou participação social voluntária. É lúdico, prazeroso e em tempo livre de obrigação profissional. Busca satisfação pessoal e expressa a cultura de um grupo e/ou sociedade. Em contextos de exclusão social, de falta de garantias de direitos básicas, o lazer pode ser visto como direito secundário, não prioritário (PERES; BODSTEIN; RAMOS; MARCONDES, 2005). Já práticas de lazer são ações humanas, apoiadas em concepções controversas que condicionam um agir, que por sua vez retroalimenta, transformando ou reafirmando estas concepções.

O Estatuto da Criança e do Adolescente (ECA) dispõe, no Art. $4^{\circ}$, o dever da família, comunidade, sociedade e poder público em assegurar o direito à criança e ao adolescente ao lazer e a convivência familiar e comunitária (BRASIL, 1990). A Organização das Nações Unidas para a Educação, Ciência e Cultura (UNESCO), segundo Abramovay et al.(2002), aponta o lazer, a arte, o esporte e a cultura como fundamentais na construção identitária de jovens. Permite aos jovens protagonismo, internalização de valores, reforço da autoestima, fortalecimento de laços de cooperação com os outros, e extravasar sentimentos de frustração entre pares. O lazer se constitui em poderosa forma de expressão e afirmação da identidade.

Por outro lado, estes autores mostram estudos do IBGE no Brasil, indicando que boa parte dos municípios não possuem equipamentos de lazer mínimos. Conforme Castro, Abramovay, Rua e Andrade (2001), 19\% dos municípios não tem biblioteca, $73 \%$ não tem museu, $75 \%$ não tem teatro e em $83 \%$ não há cinema. Além da insuficiência, Abramovay et al. (2002) salientam má distribuição dos equipamentos, com maior precariedade nas regiões de periferia, restando muitas vezes ao jovem como única opção jogar futebol.

As pesquisas sobre lazer no Brasil mostram diferentes acepções. Romera (2009) discute o papel da mídia na associação entre o lazer e uso de álcool e drogas por jovens. Em outro trabalho, Romera (2013) traz um contraponto e discute a função do esporte e do lazer na prevenção ao uso de drogas. Pratta e Santos (2007, 2013), Bastos, Bertoni e Hacker (2008) descrevem relações entre o consumo de álcool e drogas e práticas de lazer, pela disponibilidade de bebidas alcoólicas nestes contextos e a influência dos grupos como relevante. Estudos de Naia, Simões e Matos (2007), em Portugal, confirmam a relação entre as atividades realizadas pelos jovens em seu tempo livre e o consumo de substâncias ilícitas.

Conforme Silva e Silva (2011), a Organização Mundial da Saúde (OMS) define juventude como categoria sociológica que representa momento de preparação do sujeito para assumir o papel de adulto na sociedade e abrange o período dos 15 aos 24 anos. No Brasil são considerados jovens pela Política Nacional da Juventude todo cidadão entre os 15 e 29 anos (BRASIL, 2005). Muito além desta classificação etária, Novaes et al. (2006) discutem o caráter genérico e impreciso desta classificação na Polícia Nacional da Juventude: diretrizes e perspectivas. Para os autores, ser jovem no Brasil é estar imerso numa multiplicidade de identidades, posições e vivências, necessitando pensar a juventudes em termos plurais.

Para Dayrell e Gomes (2002, p. 91), ser jovem "é ao mesmo tempo uma condição social e um tipo de representação", considerando o caráter biológico e universal das mudanças corporais do indivíduo e o caráter social e histórico relacionado a esta etapa do ciclo de vida. Existem diferentes formas de preconceito relacionadas à juventude contemporânea, dentre estes as concepções da juventude como um problema, associada a situações de violência, tráfico e consumo de drogas, gravidez precoce, entre outros. Sem desconsiderar a gravidade e a necessidade de ações para estas problemáticas, Dayrell e Gomes (2002, p. 90) apontam riscos ao conceber:

o jovem de uma maneira reducionista, vendo-o apenas sob a ótica do problema, as ações em prol da juventude passam a ser focadas na busca de superação do suposto 'problema' e, nesse sentido, voltam-se 
somente para os setores juvenis considerados pela sociedade, pela escola e pela mídia como 'em situação de risco'. Tal postura inibe o investimento em ações baseadas na perspectiva dos direitos e que desencadeiem políticas e práticas que focalizam a juventude nas suas potencialidades e possibilidades.

Nas múltiplas formas de ser jovem, Oliveira e Romagnoli (2012) apontam que as situações sociais adversas, de miséria, exclusão, violência e preconceito podem afetar diretamente perspectivas e concepções de vida, favorecendo o envolvimento em situações de risco como exploração sexual, tráfico de drogas, exploração de mão de obra e outras.

O lazer também remete a diferentes compreensões. Caracteriza-se como direito básico previsto por diferentes políticas e como ação humana concreta, trazendo imbuído em si um duplo sentido: por um lado desenvolve qualidade de vida e/ou saúde, por outro, é visto como o tempo/espaço em que os sujeitos ficam expostos a diferentes riscos, como álcool, drogas, comportamentos antissociais, agressões, acidentes de trânsito, violência sexual, entre outros.

Adentrando na discussão sobre riscos, Pesce et al. (2004) os consideram eventos, acontecimentos ambientais que aumentam a vulnerabilidade para resultados negativos no desenvolvimento. Inicialmente o conceito remete a pensar em termos de fatores de risco, mas, na atualidade, propõem-se a entendê-los como mecanismos de risco, pois não são estáticos, mas processos. Seus efeitos dependem do momento, intensidade e cronicidade da exposição a certas questões, número dos fatores de risco, níveis de exposição e limites individuais para suportar determinadas experiências, definidos como tolerância ao estresse. "Condições de pobreza, rupturas na família, vivências de algum tipo de violência, experiências de doença no próprio indivíduo ou na família e perdas importantes [...]" (PESCE et al., 2004, p. 135) são exemplos de situações de risco. No entanto, os riscos podem ser moderados por fatores de proteção, possibilitando atitudes positivas frente às adversidades. Espera-se que os riscos não sejam observados de forma isolada, mas em interação com fatores de proteção. Determinados fatores de proteção potencializam outros. Enquanto os fatores de risco são eventos estressores de vida, os fatores de proteção são mediadores destas situações difíceis. Entende-se como fatores de proteção, características pessoais, familiares e ambientais, e processos de proteção, como ações diante dos riscos, capazes de provocar modificações em seus efeitos.

As respostas dos sujeitos diante da adversidade, de acordo com a Psicologia Positiva, têm sido pensadas em termos de vulnerabilidade e resiliência. No âmbito da saúde, a vulnerabilidade é uma predisposição a desenvolver comportamentos ineficazes, enquanto a resiliência é a capacidade de usar recursos cognitivos e comportamentais ativos $^{1}$ e enfrentar problemas, elaborar dificuldades e resistir aos efeitos negativos do risco. Para Sotero (2011), é preciso diferenciar vulnerabilidade e vulneração. Segundo Schramm (2008, p. 20), devemos distinguir:

a mera vulnerabilidade - condição ontológica de qualquer ser vivo e, portanto, característica universal que não pode ser protegida - da suscetibilidade ou vulnerabilidade secundária (por oposição à vulnerabilidade primária ou vulnerabilidade em geral). Ademais, os suscetíveis podem tornar-se vulnerados, ou seja, diretamente afetados, estando na condição existencial de não poderem exercer suas potencialidades (capabilities) para ter uma vida digna e de qualidade.

Sotero (2011) também coloca a vulnerabilidade como princípio ético da Declaração Universal de Bioética e Direitos Humanos (2005), que estabelece no Artigo $8^{\circ}$ :

Respeito pela Vulnerabilidade Humana e pela Integridade da Pessoa - Na aplicação e no avanço do conhecimento científico, da prática médica e das tecnologias associadas, deve ser tomada em consideração a vulnerabilidade humana. Indivíduos e grupos de vulnerabilidade especial devem ser protegidos e a integridade pessoal de tais indivíduos deve ser respeitada. (UNESCO, 2005, p. 7).

A vulnerabilidade como princípio ético, para Schramm (2008), exige distinguir graus de cuidados para os vulneráveis, aqueles, cuja dignidade e integridade estão ameaçadas, sugerindo proteção adequada, ação positiva e respeito à condição de vulnerabilidade, tanto no que tange a não ferir, como cuidar. Há a vulnerabilidade como condição humana, como sensibilidade, há a vulnerabilidade secundária como suscetibilidade em decorrência de algo e existem as condições de vulneração. Pesce et al. (2004) se referem à vulnerabilidade como falta de condições dos sujeitos; enquanto vulneração, para Sotero (2011), são situações concretas de ameaça e desproteção por frágeis condições ambientais em prover ações protetivas, ampliando a vulnerabilidade dos sujeitos. Além disto, para Schramm (2008, p. 11), há a vulneração humana que é “a condição existencial dos humanos que não estão submetidos somente a riscos de vulneração, mas a danos e carências concretas, constatáveis por qualquer observador racional e imparcial". As condições concretas de vulneração, que aumentam a vulnerabilidade, invocam “a 
obrigação moral e ética de proteção para [...] grupo de pessoas. A vulneração, como reconhecimento de vulnerabilidades corporificadas, implica modos específicos no planejamento e desenvolvimento de políticas públicas" (SOTERO, 2011, p. 815), o que requer "distinguir graus de proteção de acordo com a condição existencial de vulnerabilidade, suscetibilidade e vulneração" (SCHRAMM, 2008, p. 20).

Oliveira e Romagnoli (2012, p. 159) entendem que há processos de vulnerabilidade social a serem enfrentados como "fenômeno multicausal, multifacetado e historicamente determinado" e que exigem "estratégias dinâmicas, intersetoriais e interdisciplinares, que considerem essa multiplicidade de fatores que interagem entre si constituindo complexas redes causais". Esses processos colocam "em risco toda a potencialidade [...] atribuída à juventude por fatores diversos como a idade e sua vitalidade, colocando-a diante de situações de incerteza e instabilidade" (OLIVEIRA; ROMAGNOLI, 2012, p. 156). Estas disposições são reflexos da disponibilização por parte do Estado, mercado e sociedade de recursos materiais e simbólicos e sua relação com a não garantia de acesso a oportunidades sociais, econômicas e culturais, que geram desvantagens para o desempenho dos sujeitos (VIGNOLI e FILGUEIRA apud ABRAMOVAY et al., 2002).

Neste âmbito situa-se a importância em refletir a construção de políticas públicas de lazer. Este trabalho se propõe aprofundar as relações entre lazer juventude e exposição a riscos que podem gerar processos de vulnerabilidade secundária e/ou vulneração. Ao mesmo tempo em que busca esclarecer concepções que atravessam práticas de lazer na família, nas comunidades e nos serviços e, com isso, subsidiar discussões no âmbito da RAIA, com comunidades, famílias e jovens para qualificar o planejamento e as ações de promoção do lazer numa lógica de produção de práticas protetivas, geradoras de promoção da saúde e melhoria da qualidade de vida.

\section{Procedimentos metodológicos}

O estudo foi desenvolvido, em 2014, em um Serviço de Convivência e Fortalecimento de Vínculos, programa da Secretaria de Assistência Social voltado para jovens e, conforme a Tipificação Nacional de Serviços Sócio Assistenciais (2009), tem o propósito de prevenir a evasão escolar, promover a participação cidadã, a convivência social e o fortalecimento dos vínculos familiares. Destaca o caráter plural e singular da condição juvenil no intuito de estimular diferentes formas de expressão, interesses, formas de ser e de se posicionar do jovem no espaço público (BRASIL, 2009).

Os participantes deste estudo residem em uma região, que corresponde a abrangência de um dos seis Centros de Referência de Assistência Social (CRAS) do município. As atividades realizadas no serviço ocorrem essencialmente no contra turno escolar, sendo as principais: oficinas de artesanato, serigrafia, informática, cartonagem, esportes entre outras.

Foram realizados dois grupos focais, um com jovens de 14 a 16 anos e outro com pais ou responsáveis. Para suscitar a discussão, foi utilizado um roteiro com perguntas contendo: 1) locais na comunidade que costumam frequentar para seu lazer e de seus familiares; 2) principais práticas de lazer e com qual frequência as realizam; 3) preocupações dos familiares em relação a estas práticas; 4) perigos e riscos que percebem em suas atividades de lazer; 5) papel da comunidade na proteção dos adolescentes; 6) ideias e sugestões destes para ambientes de lazer atrativos e saudáveis. As falas dos grupos foram gravadas e posteriormente transcritas, sendo os dados analisados a partir dos referenciais teóricos.

No período de realização da pesquisa, frequentavam o programa sócio educativo 50 jovens residentes em diferentes regiões do município, em sua maioria oriundos de famílias acompanhadas por programas sociais e beneficiárias do Programa Bolsa Família ${ }^{2}$. Os sujeitos do estudo foram convidados para participação voluntária, sendo excluídos jovens e famílias residentes em outras regiões do município que não abrangiam o recorte da pesquisa. Os grupos foram realizados no Serviço de Convivência, sendo previamente agendados com apoio da coordenação do local. Participaram do primeiro grupo onze jovens, sendo quatro do sexo feminino e sete do sexo masculino. Do segundo grupo participaram doze familiares: pais, mães, um padrasto, uma avó e um homem que mantêm união estável com uma adolescente.

O estudo foi aprovado pelo Comitê de Ética em Pesquisa da Unochapecó sob protocolo n. 60/2013, obtendo-se a concordância dos participantes por meio do Termo de Consentimento Livre e Esclarecido, os quais foram informados sobre objetivos da pesquisa, o sigilo de suas identidades e a possibilidade de retirarem o consentimento a qualquer tempo. Foi obtido ainda o termo de ciência e concordância para realização da pesquisa dentro da instituição pública municipal. Para participação dos jovens no estudo, obteve-se autorização dos pais ou responsáveis, sendo garantida sua participação voluntária com seu consentimento. Para preservar sua identidade, as falas dos participantes foram designadas por Familiar ou Jovem, de acordo com o segmento, seguidas por códigos numéricos. 


\section{Resultados e discussões}

A motivação inicial desta pesquisa partiu de discursos encontrados, muitas vezes, entre os profissionais vinculados aos serviços que fazem parte da RAIA, bem como familiares e a comunidade em geral, de que o lazer dos jovens implica em seu envolvimento com situações de risco quanto ao abuso de substâncias, ações de agressão, violência ou vandalismo, entre outras. Mudando a perspectiva do olhar para o sentido atribuído pelos jovens e seus familiares ao lazer, foi possível evidenciar práticas que revelam grande interesse em ficar com amigos, jogar/brincar, atividades ao ar livre, fazer festa em família, encontros na igreja, até mesmo descansar e fazer compras.

O mapeamento dos interesses de lazer dos jovens mostrou que estes, em sua maioria, não estão relacionados com exposição a situações de risco. Isso suscita a necessária revisão de conceitos sobre práticas de lazer de jovens, que muitas vezes, tem restringido e engessado formas de olhar, perceber e caracterizar seus interesses. Os jovens reforçam constantemente o desejo de estar com amigos e fazer coisas com eles. Abramovay et al. (2002) colocam que é essencial para os jovens fazer atividades com outros, pois fortalece valores, protagonismo e cooperação, autoestima, estratégias de apoio diante de frustrações e outros. O sentido destas atividades são protetivos e facilitadores do desenvolvimento, já que promovem integração social e relacionamento grupal. Legitimar interesses dos jovens e favorecer locais e atividades que possibilitem a grupalidade é relevante para construir estratégias de promoção da saúde.

\section{Práticas e espaços de lazer, riscos e vulneração}

A figura 1 apresenta os espaços enfatizados pelos participantes da pesquisa como lugares nos quais as práticas de lazer são vivenciadas.

\section{Figura 1: Espaços de lazer referidos por jovens e familiares}

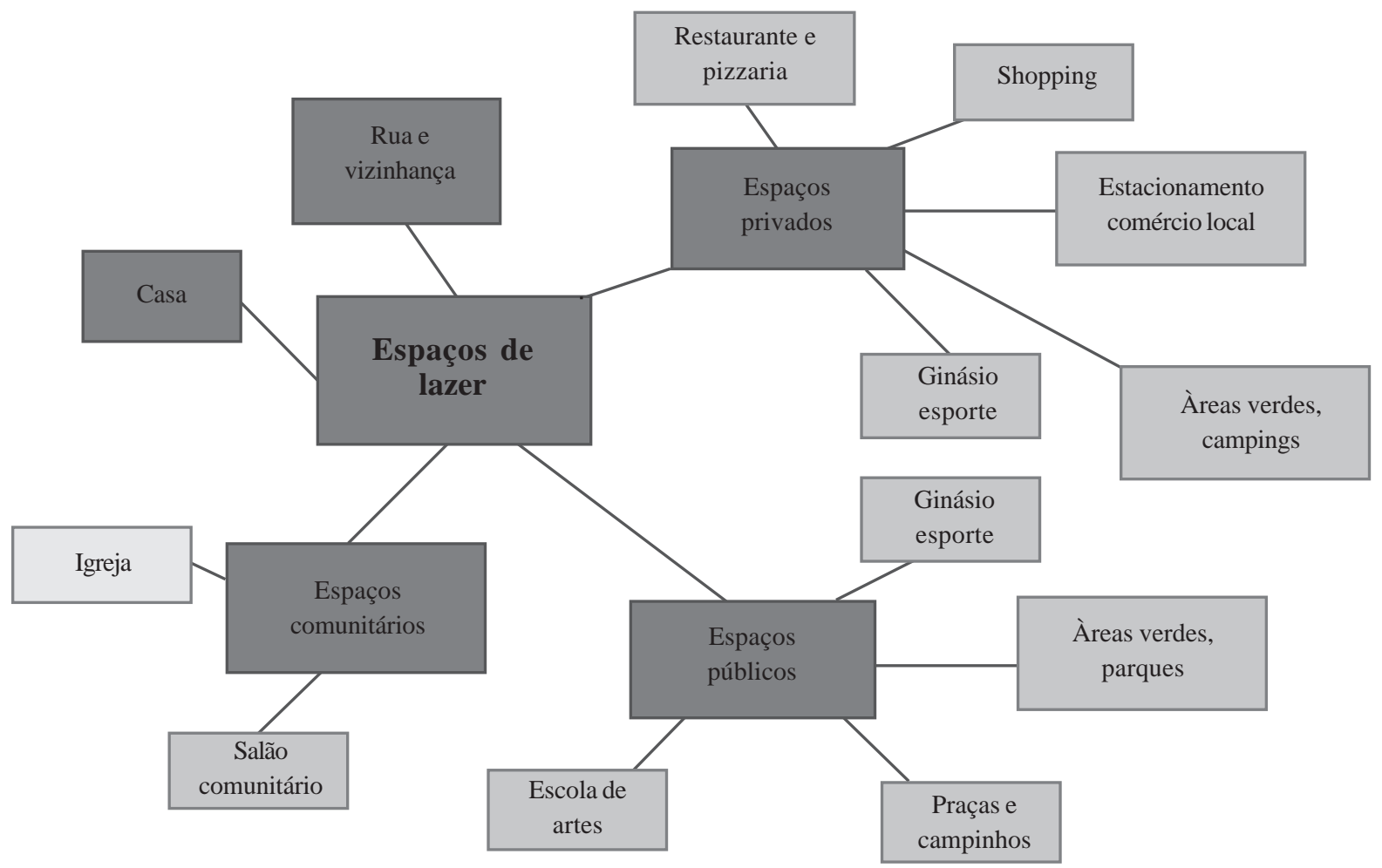

Fonte: Elaboração própria. Montado a partir dos dados empíricos coletados.

Na figura 2 estão indicadas situações percebidas pelos jovens e seus familiares que restringem ou inviabilizam o acesso e/ou o uso dos espaços de lazer, revelando-se como fatores de vulneração à medida que diminuem as oportunidades de convivência protetiva. 


\section{Figura 2: Principais fatores de risco e vulneração na relação com espaços de lazer referidos pelos jovens e familiares}

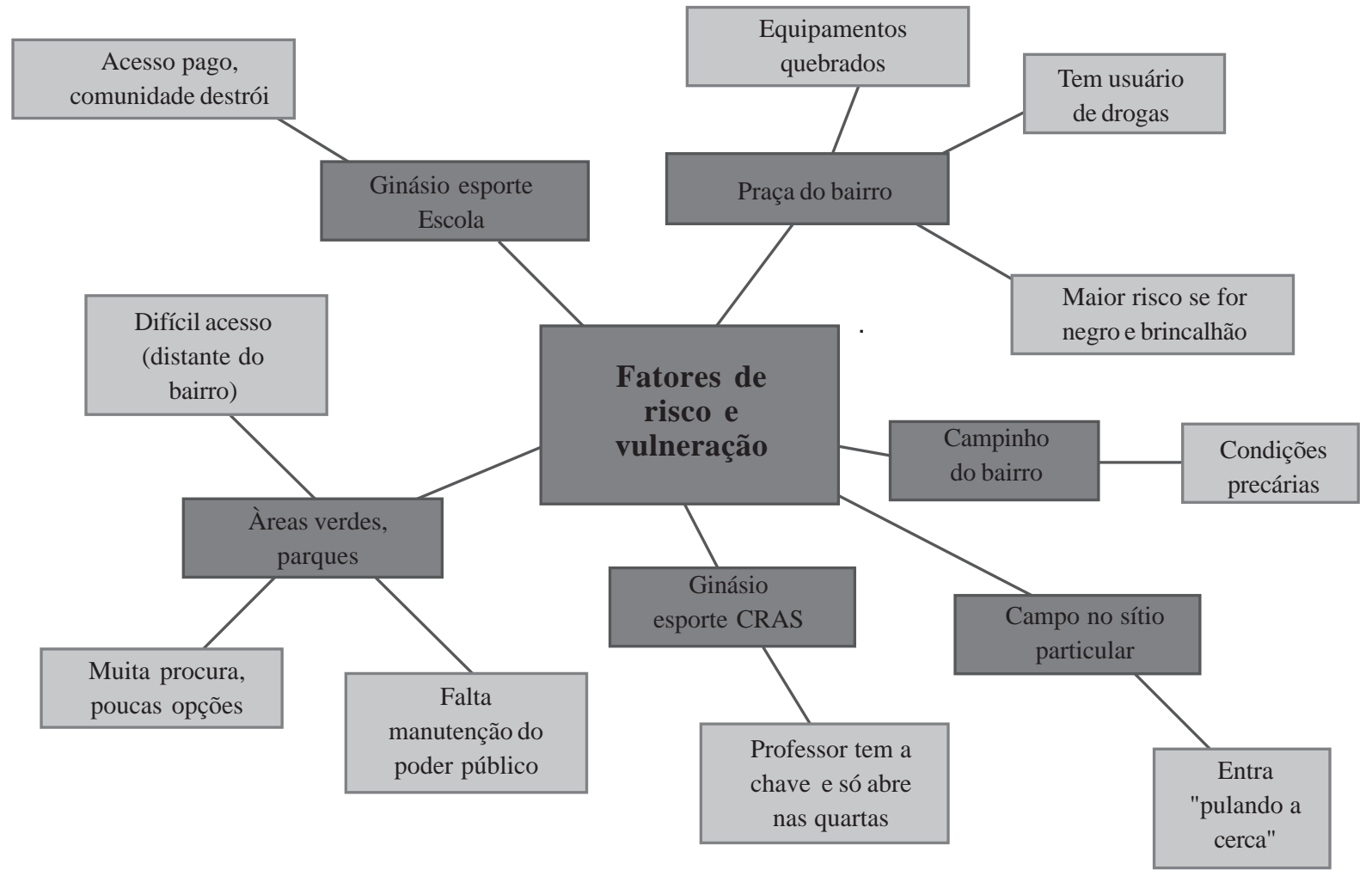

Fonte: Elaboração própria. Montado a partir dos dados empíricos coletados.

\section{a) Estar com amigos}

Ao relacionar práticas de lazer com espaços de lazer, verificamos outras questões significativas que reforçam a análise iniciada acima. Como prática mais citada, os jovens referem que gostam de encontrar-se e ficar com amigos/amigas para conversar, trocar ideias, ouvir um som ou tocar algum instrumento musical, dançar, jogar bola, ver gente ou mesmo beber refrigerante e comer pizza. Visto claramente na seguinte fala: "Eu gosto de ficar na rua, com meus amigos, jogando bola, escutando música - que eu tenho minha caixinha de som-, indo nos vizinhos" (Jovem 7). Além disto, os jovens também citaram que gostam de participar de festas, namorar e assistir a shows musicais. Estas práticas estão ligadas principalmente à espaços como as próprias residências, à casa dos amigos, à rua nas proximidades da vizinhança, mas também à avenida principal ou ao Shopping do município.

Outros espaços citados foram equipamentos públicos, como o parque de exposições municipal (Efapi), no qual são promovidos shows de abrangência regional, a Escola de Artes, que oferece cursos de natureza cultural, ou o salão da comunidade, no qual os jovens podem aprender a tocar instrumentos musicais com o apoio de voluntários. Encontrar amigos na internet, por meio do facebook também foi citado, mais relacionado à uma prática entre familiares: "A minha mãe gosta de ficar bastante no Facebook" (Jovem 5).

Atividades e espaços referidos pelos entrevistados, bem como situações ou fatores que indicam riscos e processo de vulneração ou potencias e processos de proteção, dependem da forma como estes são incorporados pelos diferentes sujeitos envolvidos, bem como das mediações construídas no ambiente que estes vivem. Entre os fatores de risco ou vulneração que os jovens referiram como presentes nesses espaços destacam-se: a intolerância de vizinhos ao barulho ou aos possíveis riscos de destruição na propriedade suscitados pelo uso da bola na rua; estarem sujeitos à ser "dispersos" pela polícia na avenida central; e, o acesso restrito aos equipamentos por ser pago ou por ser distante da comunidade, no caso do Shopping, Escola de Artes ou Efapi. Os jovens se referem ainda as práticas repressivas dos pais, no sentido de proibir encontros, namoro ou ficar até mais tarde em festas. Nessa direção, familiares consideram necessário proteger os jovens ante possíveis riscos, por meio de práticas repressivas: "[meus filhos foram] convidados para uma janta de aniver- 
sário [de 15 anos] de uma coleguinha [...]. Daí eu disse: 'vocês sabem o sistema do pai, [...] se é a noite, convida vocês dois e o pai e a mãe não, vocês não vão'. [...] Meu sistema é assim. Eu cortei na hora! Eles não gostaram muito" (Familiar 5). Tais atitudes indicam dificuldades dos pais em acompanhar mudanças de interesse dos filhos quanto ao lazer, com atitudes de mediar, acompanhar e dar liberdade gradual monitorada, fortalecendo sua capacidade de autocuidado e crítica quanto aos riscos. A autonomia requer ser desenvolvida nos jovens por meio de processos de mediação nas relações familiares e sociais, sendo apontada por Pesce $e t$ al. (2004) como fator de proteção. Nesta direção, percebem-se na comunidade dificuldades em desenvolver estratégias de acolhimento e inserção dos jovens nos espaços da vizinhança. Juntamente com o poder público, são reforçados discursos sobre lazer centrados em lógicas de controle de riscos, que defendem práticas repressivas diante das iniciativas dos jovens, e não a construção de espaços mediadores para desenvolver fatores de proteção, tampouco processos de proteção, capazes de reduzir o impacto dos riscos.

Falas dos adolescentes indicam maior produção de processos de risco, ao invés de proteção. As práticas repressivas dos pais, comunidade e poder público, incluindo a vigilância policial, parecem favorecer a busca dos jovens por espaços clandestinos, "mais escondidos", tais como novos loteamentos, sem vigilância. Os jovens referem que nestes espaços podem fazer "fervo", "escutar som, tomar gole" (Jovem 10), coisas que "não [se] faz em casa, por causa dos vizinhos" para "fazer barulho, [...] todos darem risadas, se divertir, poder gritar, falar o que quiser" (Jovem 11). Tais práticas evidenciam situações de risco a que os jovens se expõem com maior intensidade e expressam iniciativas criadas e disseminadas no município para suprir a falta de espaços acessíveis e as práticas repressivas vivenciadas. Outras práticas de risco, como beber ou fazer "sacanagem", também são citadas como diversão com amigos, relacionadas especialmente à frequentar casas de show.

Enquanto o processo de proteção busca minimizar efeitos negativos em cadeia da exposição aos riscos, a compreensão reduzida sobre mudanças de interesses dos jovens, de seus desejos em estar juntos em brincadeiras, bagunças, música, em momentos de lazer, pode produzir processos de vulneração em curso, à medida que se nega a importância destas vivências e restringem-se espaços para tal. Há inclusive que se pensar se há preservação do direito de lazer aos jovens, conforme diferentes políticas preveem. Para Oliveira e Romagnoli (2012, p. 157), este contexto é propício ao desenvolvimento de uma visão reducionista da condição juvenil como um problema social, visão esta que tem como consequência a inibição de ações e práticas voltadas para a potencialidade da juventude e seus direitos.

Por sua vez, quanto ao consumo de bebidas ou drogas, as falas dos jovens indicam uma ideia de que o uso abusivo de substâncias é uma escolha centrada no sujeito, na decisão pessoal, negando as forças de coerção exercidas pela cultura, por grupos, muitas vezes relacionadas com o status conferido pelo uso de determinadas substâncias psicoativas e minimizando os riscos dos abusos. Bretas (2010) entende que o jovem pode cometer facilmente dois equívocos diante dos riscos: negar os mesmos numa atitude de onipotência, ou achar que não há motivos para cuidar de si mesmo, em situações de baixa autoestima.

Em contrapartida, o fato de que os jovens reconhecem como lazer e valorizam o encontro com amigos para conversar, escutar música, dançar, brincar, namorar, entre outros, indica conotação positiva relativa à estabelecer relações de amizade, participar de grupos, favorecendo a integração social. Ser chamado por pares e participar de coletivos é proteção fundamental, possibilita "bom relacionamento com amigos, [...] ou pessoas significativas que assumam papel de referência segura à criança e a faça se sentir querida e amada, favorecendo a autoestima" (BROOKS; EMERY; FOREHAND, apud PESCE et al., 2004, p. 137).

Por um lado, os espaços de lazer na comunidade revelam potência protetiva, pois são espaços nos quais os jovens podem ser melhor acompanhados pelos pais ou mesmo pela vizinhança, com cuidados pautados na reciprocidade, reforçando o sentimento de pertencimento e corresponsabilidade. Contudo, outras falas revelam nestes espaços condições de vulneração quando jovens salientam práticas de preconceito de gênero (meninas sofrem maior risco de violência sexual), de cor (ser negro é estar sujeito à maior risco de violência física), ou ainda relativos ao bairro, à sua situação social (restrição do acesso ao lazer por exigir pagamento) ou a certas "marcas" que possam representar vinculação aos grupos malvistos pela comunidade ou pelo poder público (no caso de usar bonés com marcas específicas ou certas tatuagens): "Apanha! Só porque está com o boné, é revistado totalmente!" (Jovem 5).

Nessa perspectiva, a criação de alternativas as práticas repressivas representam certa resistência dos jovens diante de lógicas de controle e sujeição, indicando potência criativa e capacidade de exercer autonomia. Este movimento é considerado por Abramovay e Castro (2002, p. 146) a partir de Bordieu, semente positiva, promovendo consciência de violências simbólicas, do que aparece como arbitrário, em um "poder simbólico de subversão". Estes processos podem sugerir "desencantos, buscas, pedidos de socorro, falta de referências, projetos coletivos que mobilizam os jovens, assim como limites de uma cultura de consumo e individualismo" (ABRAMOVAY; CASTRO, 2004, p. 2). 


\section{b) Atividades de jogar ou brincar}

Como segundo grupo de práticas de lazer os jovens citam jogar ou brincar, relativo as atividades esportivas ou jogos eletrônicos. As primeiras, vinculadas ao jogar bola (futebol, vôlei e basquete), são realizadas em locais públicos ou privados, como ginásios, campo aberto (grama ou sintético) ou quadra de areia: "Não tem [...] nenhum lugar que é de graça que você pode ir! No Ecoparque não dá pra levar bola; só dá para você caminhar e conversar com seus amigos. Que nem, eu gosto muito de jogar bola, fazer esporte; daí não dá!" (Jovem 5).

Os segundos referem-se à jogar vídeo game (guitarhero, play station) ou jogos de computador, praticados em suas residências, na casa de amigos ou ainda no Shopping do município. Jogar bola tem sido um desafio - salientado pelos jovens e familiares -, à medida que os espaços (públicos e privados) apresentam restrições de acesso como: quantidade insuficiente frente à demanda; horários limitados; péssimas condições de estrutura ou manutenção (no caso da quadra de areia e de um campo em área verde, públicos): "No campinho que tem ali em cima [...], é um lugar pra piazada jogar bola e conversar. Só que é um lugar onde tem bastante sujeira: tem prego, vidro... O meu irmão, geralmente, pisa em cima e machuca o pé. É bem perigoso jogar bola lá" (Jovem 6). Outra queixa é a cobrança de taxas (ginásio público ou campo privado): "Para a piazada jogar bola [...], eles têm que pagar! Para eles ir passar uma hora, duas horas para se distrair! Não! É só pagar aquela uma hora, encerrou aquela hora, vem embora, não pode ficar mais tempo!" (Familiar 3). A restrição e precarização dos espaços de lazer são citados em Castro, Abramovay, Rua e Andrade (2001), que apontam grande parte dos municípios com poucos equipamentos de lazer e maior precariedade em comunidades não centrais.

Nestes espaços há maior restrição para as meninas, que sofrem também assédio por parte dos meninos: "devia ter mais respeito nos lugares, sabe! Têm muitos lugares que, se uma menina sair com calção curto na rua, ela é uma vadia!" (Jovem 11).

Em relação aos jogos eletrônicos, há reclamações quando tem que pagar (no caso do Shopping), mas, em especial, quando requer acesso à rede de internet, nem sempre disponibilizada em suas residências. "Roubar wi-fi" (como os jovens referem) à noite, em frente aos estabelecimentos do comércio local pode ser risco de confronto com a polícia, ainda maior quando associado ao preconceito de cor "porque ele é preto que nem nós" (Jovem 10).

$\mathrm{O}$ acesso aos espaços de lazer relativo a jogar e brincar tem sido inibido também pelas dificuldades de os jovens ou a comunidade criarem estratégias de enfrentamento aos preconceitos e, decorrentes destes, às práticas repressivas e excludentes, com maior impacto sobre o lazer de meninas e negros. Por outro lado, a crítica aos preconceitos, à precarização e redução dos espaços e equipamentos públicos e universais de lazer configura-se como potência para a mobilização dos jovens, familiares, comunidade e poder público para debater e intervir em favor da construção de espaços de lazer saudáveis na comunidade.

\section{c) Atividades ao ar livre}

Um terceiro grupo de práticas de lazer citado refere-se às atividades ao ar livre, para se divertir, caminhar, nadar, acampar, "assar uma carninha" (referindo-se à tradição regional de fazer churrasco entre familiares e amigos). Incluindo desde a praça do bairro, parques municipais, áreas verdes em encostas de rios, clubes ou campings (privados), que "Muitas vezes é cheio! Mesmo você pagando, às vezes não tem espaço!" (Jovem 10). Estes espaços foram referidos como de mais difícil acesso, por serem distantes e pagos ou, no caso da praça do bairro e do parque municipal, pelas condições precárias em que se encontram, bem como a ameaça percebida com a ocupação de usuários e traficantes de drogas.

Considerando-se os fatores associados à vulneração percebidos em relação a estes espaços, ressaltamse a falta de engajamento da comunidade e de compromisso do poder público em garantir opções em quantidade e qualidade, além de acessíveis, que favoreçam e viabilizem práticas de lazer universais. Outra situação destacada é o descuido relacionado aos locais e equipamentos existentes, tanto por parte do poder público (falta de manutenção), quanto da própria comunidade (atitudes depredatórias). Também puderam ser percebidos preconceitos quanto ao acesso aos espaços na fala de jovens, os quais defenderam a ideia de que "se você quer um lugar meio que garantido, vai ter que pagar, para não correr risco" (Jovem 11).

Por outro lado, a crítica dos jovens e familiares sobre fatores que restringem o acesso e excluem parcela significativa da comunidade das oportunidades de lazer indica potência para mobilização. Além disso, apesar de poucas e, em sua maioria, distantes da comunidade, a existência de áreas verdes, praças e parques no município, bem como a iniciativa das famílias em usufruir estes espaços, constitui-se potência protetiva relativa à prática de lazer saudável envolvendo jovens e seus familiares. No entanto, esta potência precisa ser mobilizada para que haja engajamento da comunidade em reivindicar equipamentos e produzir o cuidado destes espaços, junto ao poder público, podendo se perceber como coadjuvante deste processo. 


\section{d) Atividades em família ou em casa}

Em quarto lugar são citadas atividades em família, como almoços ou festas, podendo incluir parentes como avós, tios e primos. Estas são geralmente realizadas nas residências, em espaços como a garagem ou outro ambiente apropriado. Em algumas situações, há referência de os pais levarem ou acompanharem os filhos em festas de amigos, aniversários ou atividades realizadas na comunidade.

Nas falas dos participantes percebeu-se que festas em família constituem-se processos de vulneração ou de proteção, de acordo com as relações que os pais estabelecem com os jovens. Práticas de mediação do consumo de bebidas alcoólicas em momentos de integração familiar, por exemplo, por um lado podem constituirse situação de risco, quando reproduzem padrões de abuso; por outro lado, podem facilitar a aprendizagem de uso social de álcool, de forma ponderada. Em relação à primeira situação, percebe-se que os familiares sentem-se, muitas vezes, fragilizados no sentido de criar estratégias de acompanhamento e cuidados, não percebendo ou desconsiderando ameaças potenciais ou reais de uso abusivo de substâncias por parte dos jovens. No segundo caso, percebe-se potência protetiva quando os familiares reconhecem que o uso abusivo pode acontecer em momentos de lazer e criam estratégias de monitoramento dos filhos, prevendo ações educativas centradas na construção da autonomia e direito de escolha. Isto favorece a percepção e a valorização dos jovens quanto à convivência com familiares como espaço de lazer e diversão, promovendo a integração familiar.

De forma expressiva, a preocupação de familiares com as práticas de lazer dos filhos, bem como sua clareza sobre a importância destas para seu desenvolvimento saudável reflete potência para seu envolvimento no debate sobre lazer e risco, bem como para ações de parceria na comunidade. Este potencial pode ser fortalecido pelos profissionais à medida que mobilizem familiares, comunidade e poder público em diálogo com os jovens na busca de alternativas conjuntas em prol da construção e manutenção de espaços para o encontro com amigos como prática protetiva. Além disso, maior engajamento desses segmentos favorece a reivindicação e a construção de políticas afirmativas de práticas de lazer na comunidade.

Há ainda outras atividades citadas, tais como descansar, fazer compras e participar de encontros na igreja. Estes últimos são referidos pelas famílias como espaços de proteção, pois envolvem os jovens em ações compartilhadas com outros jovens, sob a coordenação de um adulto, evitando que permaneçam na rua ou em lugares de maior risco.

\section{Considerações finais}

Nesta pesquisa, uma das perguntas essenciais que marcou o diálogo com as falas dos participantes foi a seguinte questão: qual é o lugar que os jovens têm para se encontrar e para crescer juntos na comunidade? Por um lado, existem discursos que patologizam as práticas dos jovens quanto ao lazer, relacionando-as aos riscos e gerando preocupações. No entanto, há uma fragilização no sentido de produzir espaços públicos e nas famílias para que possam reconhecer as mudanças de interesses inerentes ao processo de crescimento, bem como criar estratégias de construção de autonomia com monitoramento gradual do jovem para que este possa refletir sobre suas escolhas, principalmente diante de riscos, como o uso de álcool e outras substâncias.

Quanto ao contato dos jovens com o álcool, um dos espaços citados desse contato ocorre nas próprias famílias, tema que merece ser aprofundado em outros estudos para entender se este contato acontece como experiência mediada de aprendizagem de uso e gestão das escolhas pessoais ou se são espaços de aprendizagens de abuso. Isso poderia ser discutido com adolescentes e familiares, refletindo sobre concepções acerca da temática e trazendo para a pauta possíveis estratégias de uso mediado. As falas dos jovens, de que estes buscam outros espaços, e espaços escondidos, como exercício de autonomia, mostra que as estratégias repressoras e de negação não tem funcionado como estratégias protetivas.

a crítica aos preconceitos, à precarização e redução dos espaços e equipamentos públicos e universais de lazer configura-se como potência para a mobilização dos jovens, familiares, comunidade e poder público para debater e intervir em favor da construção de espaços de lazer saudáveis na comunidade.

É necessário, enquanto rede de atendimento, colocar em debate discursos sobre a relação entre jovens, lazer e risco, pois há uma acepção em culpabilizar as atitudes dos jovens. O risco visto como vulnerabilidade do 
jovem diante da sua imaturidade no lazer é uma forma de reduzir as discussões, pois ignora o quanto as opções são restritas e as condutas em relação aos seus interesses são repressoras. Isso gera condições de vulneração, como colocam Schramm (2008) e Sotero (2011), fragilizando vivências de integração e participação social dos jovens, sem compreender o lazer como direito e sua potência na produção de experiências de desenvolvimento. É preciso transcender acepções de controle de risco e investir em espaços de integração social de jovens, dos jovens com suas famílias e na comunidade.

\section{Bibliografia}

ABRAMOVAY, M.; et al. Juventude, violência e vulnerabilidade social na América Latina: desafios para políticas públicas. Brasília: UNESCO/BID, 2002.

; CASTRO, M. G. Jovens em situação de pobreza, vulnerabilidades sociais e violências. Cadernos de Pesquisa, São Paulo, s/v, n. 116, p. 143-176, jul. 2002.

. Juventudes no Brasil: vulnerabilidades negativas e positivas. In: I Congresso da Associação Latino Americana de População ALAP, 2004, Caxambu/MG. ANAIS. Caxambu: UNICAMP, 2004, p. Disponível em: http://www.abep.nepo.unicamp.br/ site_eventos_alap/PDF/ALAP2004_295.PDF. Acesso em: 10 ago. 2015.

BASTOS, F. I.; BERTONI, N.; HACKER, M. A. Consumo de álcool e drogas: principais achados de pesquisa em âmbito nacional. Rev. Saúde Púb., São Paulo, v. 42, suppl. 1, p. 109-117, 2008.

BRASIL. Lei n ${ }^{\circ} 8.069$, de 13 de julho de 1990. Dispõe sobre o Estatuto da Criança e do Adolescente e dá outras providências. Diário Oficial da República Federativa do Brasil, Brasília, 1990.

Lei 11.129, de 30 de junho de 2005. Institui o Programa Nacional de Inclusão de Jovens - ProJovem; cria o Conselho Nacional da Juventude- CNJ e a Secretaria Nacional de Juventude; altera as Leis nos 10.683, de 28 de maio de 2003, e 10.429, de 24 de abril de 2002; e dá outras providências. Disponível em: <http://www.planalto.gov.br/ccivil_03/_Ato2004-2006/2005/Lei/L11129.htm>. Acesso em: 10 jun. 2015.

. Ministério do Desenvolvimento Social e Combate à Fome (MDS). Secretaria Nacional de Assistência Social. Tipificação Nacional de Serviços Socioassistenciais. Documentos Base: Brasília, jun. 2009.

BRETAS, J. R. da S. Vulnerabilidade e Adolescência. Rev. Soc. Bras. Enferm. Ped., São Paulo, v. 10, n. 2, p. 89-96, dez. 2010.

CASTRO, M. G.; ABRAMOVAY, M.; RUA, M. G.; ANDRADE, E. R. Cultivando vida, desarmando violências: experiências em educação, cultura, lazer, esporte e cidadania com jovens em situação de pobreza. Brasília: UNESCO, Brasil Telecom, Fundação Kellogg, Banco Interamericano de Desenvolvimento, 2001.

DAYRELL, J. T.; GOMES, N. L. A. Juventude no Brasil: questões e desafios. In: MATOS, M.; GOMES, N. L.; DAYRELL, J. (Orgs.). Cidadania e a luta por direitos humanos, sociais, econômicos, culturais e ambientais. Belo Horizonte, DCP/Fafich/UFMG, p. 89-113, 2002. DUMAZEDIER, J. Lazer e cultura popular. São Paulo: Perspectiva, 2001.

NAIA, A.; SIMÕES, C.; MATOS, M. G. Consumo de substâncias na adolescência. Revista Toxicodependências, Lisboa/Portugal, v. 13, n. 3, p. 23-30, 2007.

NOVAES, R. C. R.; CARA, D. T.; MOREIRA DA SILVA, D.; PAPA, F. de C. Política Nacional da Juventude: diretrizes e perspectivas. São Paulo: Conselho Nacional de Juventude, Fundação Friedrich Ebert, 2006.

OLIVEIRA, L. da S.; ROMAGNOLI, R. C. Juventude, Vulnerabilidades e Políticas Públicas. Revista Perspectivas em Políticas Públicas, Belo Horizonte, v. 5, n. 9, p. 151-163, jan./jun. 2012.

PESCE, R.; et al. Risco e proteção: em busca de um equilíbrio promotor de resiliência. Psicologia: Teoria e Pesquisa, Brasília, v. 20 n. 2, p. 135-143, mai./ago. 2004.

PERES, F.F.; BODSTEIN, R.; RAMOS, C. L.; MARCONDES, W. B. Lazer, esporte e cultura na agenda local: a experiência de promoção da saúde em Manguinhos. Ciência e Saúde Coletiva, Rio de Janeiro, v. 10, n. 3, p. 757-769, jul./set. 2005.

PRATTA, E. M. M.; SANTOS, M. A. Lazer e uso de substâncias psicoativas na adolescência: possíveis relações. Revista Psicologia: Teoria e Pesquisa, Brasília, v. 23, n. 1, p. 43-52, mar. 2007.

; ___ Fatores de risco para o uso na vida e no ano de álcool entre adolescentes do ensino médio. SMAD - Revista Eletrônica Saúde Mental Álcool e Drogas, São Paulo, v. 9, n. 1, p. 18-24, jan./abr. 2013.

ROMERA, L. A. Drogas e mídia: influências no lazer da juventude. Revista Licere, Belo Horizonte, v. 12, n. 3, p. 1-18, 2009.

. Esporte, Lazer e Prevenção ao uso de drogas: dos discursos equivocados aos caminhos possíveis. Revista Licere, Belo Horizonte, v. 16, n. 4, p. 1-19, dez. 2013.

SCHRAMM, F. R. A. Bioética da Proteção: ferramenta válida para enfrentar problemas morais na era da globalização. Revista Bioética, Brasília, v. 16, n. 1, p. 11-23, 2008.

SILVA, R. S.; SILVA, V. Política Nacional de Juventude: trajetórias e desafios. Caderno CRH, Salvador, v. 24, n. 63, p. 663-678, set./dez. 2011.

SOTERO, M. Vulnerabilidade e Vulneração: população de rua, uma questão ética. Revista de Bioética, Brasília, v. 19, n. 3, p. 799-817, 2011. 
UNESCO. Declaração Universal sobre Bioética e Direitos Humanos. Brasília: Cátedra Unesco de Bioética da Universidade de Brasília/ Sociedade Brasileira de Bioética; 2005.

\section{Notas}

1 Direcionada "para a emoção (esforço para regular o estado emocional associado ao estresse) ou focalizada no problema (esforço para agir na origem do estresse, tentando modificá-lo)" (PESCE et al., 2004, p. 137).

2 Famílias que possuem renda familiar per capita de até R $\$ 154,00$ (BRASIL, Decreto n. 8.232, de 30 de abril de 2014, Regulamenta o Programa Bolsa Família, Diário Oficial da República Federativa do Brasil, Brasília, 2014).

\section{Daiana Cristina Sebenello}

daiasebenello@gmail.com

Especialista em Proteção de Direitos e Trabalho em Rede pela Universidade Comunitária da Região de Chapecó (UNOCHAPECÓ)

Psicóloga do Centro de Referência Especializado em Assistência Social (CREAS)

\section{Liane Keitel}

lianekeitel@gmail.com

Doutoranda do Programa de Pós-Graduação Interdisciplinar em Ciências Humanas da Universidade Federal de Santa Catarina (UFSC)

\section{Maria Elisabeth Kleba}

lkleba@unochapeco.edu.br

Doutorado em Filosofia pela Universidade de Bremen - Alemanha

Professora dos Programas de Pós Graduação em Políticas Sociais e Dinâmicas Regionais e em Ciências da Saúde da Universidade Comunitária da Região de Chapecó (Unochapecó)

\section{Secretaria da Assistência Social (SAS) de Chapecó}

Rua: Clevelândia, $540 \mathrm{E}$

Chapecó - Santa Catarina - Brasil

CEP: 89.802-405

\section{UFSC}

Campus Universitário - Trindade

Florianópolis - Santa Catarina - Brasil

CEP: $88.040-900$

\section{Unochapecó}

Avenida Senador Atílio Fontana, 591 - E

Chapecó - Santa Catarina - Brasil

CEP: 89.809-000 